\title{
ARTIFICIAL INTELLIGENCE AND KNOWLEDGE MANAGEMENT
}

\author{
Hugo Cesar Hoeschl'; Vânia Barcellos ${ }^{3}$ \\ ${ }^{1}$ WBSA Intelligent Systems S.A., ${ }^{2}$ Research Institute on e-Gov, \\ Juridical Intelligence and Systems - IJURIS ; ${ }^{3}$ Federal University of \\ Santa Catarina - Program of Post-Graduation in Engineering and \\ Knowledge Management \\ hugo@wbsa.com.br; vania@ijuris.org \\ http://www.ijuris.org
}

\begin{abstract}
This article intends to make an analysis about the Artificial Intelligence (AI) and the Knowledge Management (KM). Faced with the dualism mind and body how we be able to see it AI? It doesn't intent to create identical copy of human being, but try to find the better form to represent all the knowledge contained in our minds. The society of the information lives a great paradox, at the same time that we have access to an innumerable amount of information, the capacity and the forms of its processing are very limited. In this context, institutions and centers of research devote themselves to the finding of ways to use to advantage the available data consistently. The interaction of the Knowledge Management with Artificial Intelligence makes possible the development of filtering tools and pre-analysis of the information that appear as a reply to the expectations to extract resulted optimized of databases and open and not-structuralized source, as the Internet.
\end{abstract}

\section{INTRODUCTION}

For Castells [1] the technology does not decide to society and neither the society writes the course of the technological transformation, since factors, including creativity and enterprising initiative, intervene in the trial of scientific discovery, technological innovation and social application, so that the final result depends on a complex interactive standard. While the technologies of the information advance, the gears,

Please use the following format when citing this chapter:

Hoeschl, H.C., Barcellos, V., 2006, in IFIP International Federation for Information Processing, Volume 217, Artificial Intelligence in Theory and Practice, ed. M. Bramer, (Boston: Springer), pp. 11-19. 
persons and technologies, go altering their objectives and originating an endless cycle of renewal. Inside that cycle presents-itself of clear form the dizzy evolution of the technology of the data processing, that has amount of studies dedicated to the reproduction of abilities and human capacities such the manuals, as much as the intellectuals, that is the Artificial Intelligence (AI). The intelligence is more than the faculty of learn how, apprehend or understand, interpret and, mainly adapt itself to the situations.

The present study search flow through about the dualism mind and body and the paper of the AI in his incessant search of automation of man (mind and body) (item 2), right away we are going to show an join between AI and Knowledge Management (item 3), showing the present importance of itself to automate the knowledge in the companies. We will show at the end (item 4) the evolution of the studies in AI carried by the Author and his Team and its application.

\section{AI AND DUALISM: MIND AND BODY}

Suppose a robot in a factory of cars and that we be able to ask it what is his opinion about mind and body. Evidently that creature will not be able to answer promptly, therefore it will have that to inspect before its models, as is programmed for carry out determined functions, for example adapting some piece or performming the painting of the vehicle that is passing over the caterpillar, probably will not obtain no answer.

There have been many discutions about questions of philosophical order and epstemological, questioning any possibility of Artificial Intelligence (AI). It would be possible the construction of an intelligence or similar conscience of human being in a machine? Human intelligence in its biological and animal concepts?

Many authors as John Searle, says that despite a machine could speak chinese language by resources as examining and comparing data table and binary references this doesn't grant that this machine can really understand and speak the language. It means that whether the machine can realize Turing Tests doesn't grant that it is as conscious as any human being.

The possibility of translating human intelligence to plastic artificial base has a clear limit: If intelligence can be generated from these elements, it must be necessarilly different from human one, because results happen from different human elements.

However they have not been trying to replace human being or to create artificial mind and body, but to replicate special activities and jobs using human being way, as using special robots to save life in a burning, earthshake or anyother place dangerous for human staff get. 
Because of discussion of possibility of generate artificial intelligence scientists have being gathering many knowledge since early $50^{\text {th }}$, these studies have being getting more and more interests because of commercial applications.

Researches in AI are related to areas of application that involve human reasoning, trying to imitate it and performing inferences. As Savory [22] these areas of application that are generally enclosed in the definitions of $\mathrm{AI}$ include, among others: intelligent systems or systems based on knowledge; intelligent / learning systems; understanding / translation from natural language; understanding / voice generating; analysis of image, scene in real time and automatic programming.

Notice, then, an introductory and superficial vision, about how artificial intelligence can be defined Pfaffenberger [10]: "Artificial intelligence - The field of the computer sciences that intends to perfect the computers endowing them with some peculiar characteristics of human intelligence, as the capacity to understand natural language and to simulate the reasoning in uncertainty conditions."

The following are important aspects of AI, as Rabuske [11], among others: development of heuristical methods for the solution of problems; representation of knowledge; treatment of natural language; acquisition of knowledge; artificial reasoning and logics and tools. Amongst its main applications, we have the following: mastering systems; processing of natural language; recognition of standards; robotics; intelligent databases; test of theorems and games.

Using of intelligent techniques and trying to develop computer applications provided of logical or structured cases database, to help in the task of the study of facts involves a difficult work.

For Nonaka [7], the cartesian dualism between subject and object or mind and body started from the budget of that the essence of a human being is the rational thoughtful. This thoughtful life seeks the knowledge isolating itself off the remainder of the world and off the others human being. But the imposed contemporary challenges to the cartesian dualism emphasized the importance of some forms of interaction between the self and the external world in the search of the knowledge.

For Choo [2] the needs of information are many times understood like the cognitives necessities of a person: faults or weakness of knowledge or comprehension that can be expressed in questions or topics set to a system or source of information. Then to satisfy cognitive necessity, would be to store the information that answers to what was asked. Then, returning back to our robot in a factory of cars, if a machine in which was installed some system of intelligent search, the answer would be immediate and satisfactory. In that case, the 
techniques and models of $\mathrm{AI}$ are necessary for an emotional and affectionate search of the humanity that seeks the knowledge.

\section{AI AND KNOWLEDGE MANAGEMENT}

The Italian sociologist, Domenico di Masi, in his book "O Ócio Criativo", speaks about the war between the companies, in that dispute the concurrent commercially want destroy each other, but when a company is defeated, will not be destroyed, but assimilated. This means, search the patrimony of know-how, of men and of ideas, so that is powerfull to improve the productive units instead of eliminate-her.

The knowledge became to be the focus of the business leaders, that seek way of increasing the performance of its organizations. They will assure the viability and the supported success. Methods and techniques to acquire, represent, share and maintain the knowledge did itself necessary, therefore is in all of the places (software, persons, organizations, nature, among others), and in all the forms, as for example, in a base of facts, in the person, in an organizational practice shared tacitly, or to even in a robot.

In that sense, Choo [2] emphasizes that the creation of extensive knowledge the capacities of the organizations elevating the level of specialization of his own members and learning with persons of outside of his scopes. The same author says that the external and internal ways of creation of knowledge occur in a broader organizational context, defined by an evaluation of the new knowledge regarding the strategic purpose of the organization, an appreciation of his essential capacities, an estimate of the technological potential and of the market, and the recognition that the operational innovations demand the support of new social systems of information.

Like this arose the Knowledge Engineering in late 70th, before sight barely as a discipline of the AI with the objective of creating approaches and tools to build systems based in the knowledge. It researches carried out in that area permitted the knowledge models structures construction, their systematization and, mainly, to their reuse.

In the early the Knowledge Engineering was involved with the art of build specialists systems, systems based in the knowledge and intensive knowledge information systems, summarizing everything, systems based in the knowledge. The systems based in the knowledge are arising from of the AI.

For Muñoz-Seca [8] despite of intangibility of the knowledge, to be able to handle it physically, needs its transformation in structures stuff. The knowledge must be incorporated to a physical structure that is able 
to be transformed by very well established physical methods and from the which can be extracted off new ones by sensorial methods. The knowledge in pure form is not sufficient to satisfy all the needs of the economy. The support for the mind should be supplemented with the support for the body. Consequently, the knowledge should be transformed also in fit entities inside the basic trials of the company and of the society. The materialization of the knowledge should be translated in a form that can be manipulated, stored, transmitted, restrored and used easily, without have of appeal to the person that originated it.

To capture all the knowledge process it, store it and reuse it became the big challenge of the technology that has been finding in the techniques of AI intelligent solutions over of the last decades.

\section{RESEARCHES IN AI - EVOLUTION AND APPLICATIONS}

We will illustrate the application of AI through some empirical procedures adopted by the author and his team.

The team has a multidisciplinary character, built by researchers with expressive scientific and technical qualification, with formation in distinct areas of the knowledge, such as: Science of the Computation, Right, Administration, Engineering of Output, Systems of Information, Psychology, Science of the Information, and other, graduated as post doctorate, doctorate and master. It produces since 1999 methodologies, software, everybody with techniques and approaches of AI accepted by the national scientific community and international. Of that output, detach the following:

Starting with the methodology CBR - Case Based Reasoning is used in parts with techniques of retrieval of literal information, presenting a superior performance to the traditional data bases. For in such a way, had been developed two new technologies for the team the Structured Contextual Search - SCS and the Dynamically Contextualised Knowledge Representation (DCKR).

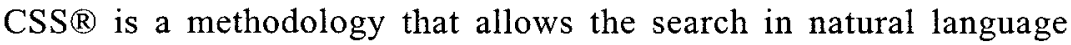
through the context of the information contained in the knowledge base, thus breaching, the search paradigm by means of key words and connectors, making it possible for the user to describe a number of characters presented by each consultation, allowing thus, a more elaborated conception of the search. The research is considered ' contextual ' and 'structured 'because of the following reasons: 1 . We take into consideration the context of documents stored at the formation 
of the rhetorical structure of the system 2. This context guides the process of adjustment of the entrance as well as the comparison and election of documents; 3 . At the moment of the elaboration of the consultation, the entrance is not limited to a set of words, or the indication of attributes, being able to assume the format of a question structured by the set of a long text is added to the possibility of operating dynamic weights on specific attributes, that work as ' filters ' and make a preliminary election of documents to be analyzed.

DCKR ${ }^{\circledR}$ consists of a dynamic process of analysis of the general context that involves the problem focused. It makes comparisons between the context of documents, enabling the accomplishment of a more precise search and with a better quality. Moreover, the documents are retrieved through pre-determined indexes, that can be valuated by the user when consulting. This technique implies a significant increment in the performance in knowledge structured systems.

Digesto $®$ - Site of legal search (www.digesto.net), that enables to the user the recuperation of documents regarding doctrine, jurisprudence, legislation and legal articles. It is a tool for searching in

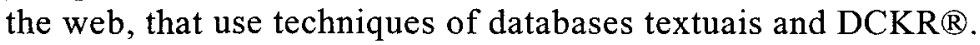

Alpha Themis ${ }^{\circledR}$ - Intelligent software for the retrieval of the knowledge contained in the "resolutions" of the national courts. It is a system of legal technology, one of the first ones in Brazil to unite Artificial Intelligence and Law. It uses techniques of textual Data base and CBR.

Jurisconsulto $(\mathbb{B}$ - Innovative system to retrieve sentences in computerized data bases through CBR. It uses techniques of textual Data Base and CBR.

Olimpo $($ - The system has its performance centered in the combination of aspects derived from CBR and from the representation of added literal information to an suitable organization of knowledge the referring to the resolutions of the Security Council of the ONU, what allows the retrieval of texts with characteristics similar to the information supplied by the user in natural language. New documents are automatically enclosed in the knowledge base through the extraction of relevant information through a technique called DCKR $B$. Concepts of CBR and techniques of information retrieval have been applied for a better performance of the system, resulting in the methodology called $\operatorname{SCS}($.

And the last, the sytem that fusing the Management of the Knowledge and Artificial Intelligence, called System KMAI. It will be discoursing about the incorporation of this revolutionary model of analysis of information, that it initiates with a methodology called Dynamically Contextualised Knowledge Representation (DCKR) 
supported by specific tools to the technology quoted and finishes with intelligent algorithms of recovery of information called Structured Contextual Search (SCS). Other already spread out cutting-adge technologies which collaborate for the transformation of information in knowledge will also be approached.

The present story intends to demonstrate system KMAI, as well as its tools and respective phases: engineering of the knowledge, collecting and storage of information, final analysis and diffusion.

KMAI- Knowledge Management with Artificial Intelligence is, before anything, a concept. It aims at being a strategical differential in the organizations of the knowledge that intend to acquire competitiveness through the processing of information for decision taking.

This concept initially integrates the Knowledge Management with the Intelligence of symbiotic form, considering that, in a systemic form, the last one belongs to the first one. To produce intelligence alone is possible with the processes of management of the knowledge or, still, to produce strategical information (knowledge) the rude information (data) must be organized. The catalytic element of the reaction of this fusing of references is Artificial Intelligence, which adds value to the preanalyses and the discovery of occult knowledge (knowledge discovery), through its capacity of mathematical processing, computational and simulation of analytical human functions.

To complete the output of the last years, was thrown recently in the internet the ONTOWEB $\mathbb{B}$ (www.ontoweb.com.br) that is an information analysis system that enables a research contextualised in the sources accessed. The kernel of this technology is focused in the new era of the internet, in the which semantic and ontologies work together to increase the prominent information search trial in documents of the web. The utilization of ontologies permits to the ONTOWEB® activate a systematic completely innovative one in the location of documents by considering the context of the matter that is being researched. The ontologies build a pre existing net of concepts inter-related that expand the concept used, driven the system to the setting that it fits. It lets the ONTOWEB $(B)$ locate, automatically, which records in their base have more resemblance with the text digitated.

Using modern techniques of Artificial Intelligence, following down

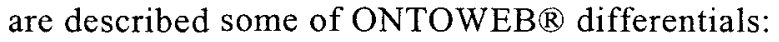

- Possibility of using over more than 10.000 words for analysis: the field of research is not limited to the key words or to simple expressions of search;

- Lines graphic generation in the answer: It is possible to get visual accompany of the variation of the matter researched in 
the time, generating subsidies for a more efficient qualitative analysis;

- Utilization of ontology contextualized in the trial of recuperation expanding the concepts used in the research and identifying its context is possible locate the best documents fit to the demand requested;

- Presentation of the result based in similarity: its answers organization criterion is purely technical, guaranteeing that the records will be presented in decreasing order of resemblance with the matter researched.

\section{CONCLUSION}

We tried in this work, even in synthetic way, flow about the importance of the AI, therefore many critics arise, many times by absence of knowledge to what is being done of research in that area.

The researches in IA opened a true fan of systems that use its techniques, that are since games, systems specialists, neural nets, recognition of hand writing, graphic computation, multiagents systems, translator and Chatter Bots (robots of software for conversation) among others.

Upon trying to join AI and Knowledge Management the Authors had the intention of showing how much the techniques of AI are able to help in this task. There are needs of information in the economic world, the information are spreaded, the knowledge is contained in persons and documents, then the application of techniques of AI to acquire, store, prosecute and reuse, generating more and more innovations in the world of the business is necessary.

For Goswami [3] one of the biggest problems for the computer is to work with the creativity, therefore are competent in the remixing of objects inside contexts supplied by the programmer, but cannot discover news contexts. However humans can do that because of our not local conscience, jumps outside from the system, and like this we generate something news in an entirely new context. The creativity is, fundamentally, not local way of cognition. The application developed by the Author and his team is an example of innovation, because started from techniques and models of $\mathrm{AI}$, created intelligent systems to manage the knowledge, therefore will not have loses of time seeking information or digital and physical files, the information, graphic and analyses, are in the screen just waiting to get a choice, giving a jump outside of the system using all its creativity. 


\section{REFERENCES}

1. CASTELlS, Manuel. A sociedade em rede (A era da informação: economia, sociedade e cultura; v.1). São Paulo, Paz e Terra, 1999.

2. CHOO, Chun Wei. A Organização do Conhecimento. São Paulo: Ed. SENAC, 2003.

3. GOSWAMI, Amit.O Universo Autoconsciente como a consciência cria o mundo material. Trad. Ruy Jungmann. $3^{\mathrm{a}}$ ed.; Ed. Rosa dos Tempos; 2000.

4. HAMIT, Francis. A realidade virtual e a exploração do espaço cibernético. Rio de Janerio: Berkley, 1993.

5. HOESHL, Hugo Cesar. Tecnologia da Informação Jurídica para o Conselho de Segurança da ONU. Ed. Papel Virtual; Rio de Janeiro; 2002.

6. HOESHL, Hugo Cesar et al. SAEI Management, an application of KMAI Knowledge Management with Artificial Intelligence. 34th Argentine Conference on Informatics and Operational Research http://www.cerider.edu.ar/jaiio34/inicio.htm1

7. NONAKA, Ikujiro; TAKEUCHI, Hirotaka. Criação de Conhecimento na Empresa: Como as grandes empresas japonesas geram a dinâmica da inovação. Rio de Janeiro: Campus, 1997.

8. MASI, Domenico de. O Ócio Criativo. Entrevista a Maria Serena Palieri; tradução de Lea Manzi; Rio de Janeiro: Sextante, 2000.

9. MUÑOZ-SECA, Beatriz.; Riverola Josep. Transformando conhecimento em resultados: a gestão do conhecimento como diferencial na busca de mais produtividade e competitividade. Trad. Carlos Racca. São Paulo: Clio Editora; 2004.

10. PFAFFENBERGER, Bryan. Dicionário dos usuários de micro computadores. Rio de Janeiro: Campus, 1993.

11. RABUSKE, Renato Antonio. Inteligência Artificial. Florianópolis: Ed. Ufsc, 1995.

12. SAVORY, S. E.(editor), "Some Views on the State of Art in Artificial Intelligence" em "Artificial Intelligence and Expert Systems", Ellis Horwood Limited, 1988, pp. 21-34, Inglaterra . 